\title{
EFEITO DA DESFOLHA NA ALTURA DE PLANTAS E PRODUTIVIDADE DE GRÃOS DE CANOLA (Brassica
} napus L.)

\author{
Cadmo João Onofre Gregory Dos Santos ${ }^{1}$, Leidiana da Rocha², Arno Bernardo Heldwein ${ }^{3}$, Angelica Durigon ${ }^{3}$, \\ Astor Henrique $\mathrm{Nied}^{3}$, Bruno Octavio Milanese ${ }^{1}$
}

\begin{abstract}
${ }^{1}$ Engenheiros Agrônomos, Universidade Federal de Santa Maria (UFSM), Santa Maria/RS-CEP: 97105-900
${ }^{2}$ Doutoranda em Agronomia, Programa de Pós-Graduação em Agronomia, Centro de Ciências Rurais, Universidade do Federal de Santa Maria (UFSM), Santa Maria/RS-CEP: $97105-900$

${ }^{3}$ Professores, Departamento de Fitotecnia, Centro de Ciências Rurais, Universidade Federal de Santa Maria (UFSM), Santa Maria/
\end{abstract} RS-CEP: $97105-900$

*Autor para correspondência: Leidiana da Rocha, leidi-r1@hotmail.com

RESUMO: A redução da área foliar das plantas interfere no potencial fotossintético e ocasiona perdas significativas no potencial de rendimento de grãos das culturas agrícolas. $O$ objetivo desse trabalho foi avaliar 0 efeito da desfolha total na altura de plantas e produtividade final de grãos de canola em solo que apresenta má drenagem natural. Foi utilizado o delineamento inteiramente casualizado, com parcelas de $0,4 \mathrm{~m}$ de largura $\mathrm{x}$ $1 \mathrm{~m}$ de comprimento sub-subdivididas (trifatorial $2 \times 4 \times 4$, onde fator $A=$ solo com e sem drenagem artificial na parcela principal; fator $C=$ cultivares Hyola 433 , Hyola 76 , Diamond e Alht B4 na subparcela, e fator $D=$ desfolha total no início, pleno e final da floração na subsubparcela), com duas repetições cada tratamento. A desfolha foi realizada em $1 \mathrm{~m}$ linear na fileira central de cada subparcela e a altura medida em 4 plantas de cada parcela. As variáveis passaram por análise de variância ( $5 \%$ de probabilidade de erro) e os resultados significativos foram comparados pelo teste de Skott-Knott. Não houve interação tripla significativa tanto para a altura de plantas quanto para produtividade. Houve diferença significativa de altura de plantas entre os tratamentos com e sem drenagem sob as diferentes épocas de desfolha e entre as cultivares utilizadas. As cultivares Hyola 433 e Diamond apresentaram alturas constantes em diferentes épocas de desfolha. A produtividade é afetada significativamente pelo fator drenagem, apresentando maiores valores no solo com drenagem. Todas as cultivares apresentaram baixa produtividade quando realizada a desfolha no início da floração.

PALAVRAS CHAVE: Excesso hídrico. Fonte-dreno. Área foliar. Fase reprodutiva. Rendimento.

\section{EFFECT OF DESFOLIATION IN PLANT HIGHT AND GRAIN PRODUCTIVITY IN CANOLA (Brassica napus L.)}

ABSTRACT: Reduction of leaf area in plants interferes with the photosynthetic potential and causes significant losses in grain yield potential of the agricultural crops. The objective of this study was to evaluate the effect of total defoliation in the height plants and final grain yield of canola in soil with poor natural drainage. A completely randomized design with plots of $0.4 \mathrm{~m}$ wide $\times 1 \mathrm{~m}$ long sub-subdivided was used (trifactorial $2 \times 4 \times 4$, where factor $A=$ soil with and without artificial drainage in the main plot, factor $C=$ cultivars Hyola 433, Hyola 76, Diamond and Alht B4 in the subplot, and factor $D=$ total defoliation at the beginning, full and final of flowering in the sub-subplot), with two replicates each treatment. The defoliation was performed in $1 \mathrm{~m}$ in the central line of each subplot and the height measured in 4 plants of each plot. The variables were analyzed by analysis of variance ( $5 \%$ probability of error) and the significant results were compared by the Skott-Knott test. There was no significant triple interaction for both plant height and productivity and. There was a significant difference in plant height between treatments with and without drainage under the different times of defoliation and among the cultivars used. The cultivars Hyola 433 and Diamond presented constant heights in different times of defoliation. The productivity is significantly affected by the drainage factor, presenting higher values in the soil with drainage. All cultivars presented low productivity when defoliation was performed at the beginning of flowering.

KEYWORDS: Water excess. Source-drain. Leaf area. Reproductive phase. Yeld. 


\section{INTRODUÇÃO}

A canola (Brassica napus L. variedade oleifera) é uma espécie oleaginosa pertencente à família Brassicaceae cultivada na estação de inverno e apresenta alto potencial produtivo, o que a torna importante alternativa para o sistema de rotação de culturas, principalmente para a região tritícola do Sul do Brasil, onde as temperaturas no inverno são favoráveis para o seu crescimento e desenvolvimento. Além disso, sua inserção no sistema de cultivo de inverno reduz os problemas fitossanitários para as culturas subsequentes no verão como a soja e o milho, o que contribui para um melhor sistema produtivo de grãos e pelo retorno econômico que se tem obtido.

O estado do Rio Grande do Sul é o maior produtor nacional de grãos de canola, no entanto, as médias de produtividade ainda são muito inferiores se comparadas ao potencial produtivo da cultura (Conab, 2017). Para alcançar maiores produtividades, faz-se necessário um maior entendimento da interação dos fatores ambientais para com os fatores fisiológicos das plantas, identificando genótipos mais adaptados às condições climáticas locais e que apresentam maiores respostas produtivas. Também, faz-se necessário compreender as interações e o processo de fontedreno das plantas (folhas, caules, síliquas e raízes), em relação à produtividade, sob diferentes condições ambientais, para que seja possível aumentar a produtividade das lavouras a nível comercial.

Nas plantas, as folhas são os principais órgãos fontes responsáveis pela sintetização de assimilados a partir da fotossíntese. 0 fluxo destes assimilados, regido por processos metabólicos e de transporte, que ocorre em um sistema de fonte-dreno, resulta na distribuição de massa seca nos diferentes órgãos da planta (Duarte e Peil, 2010). A análise e o estudo de desfolha, bem como o momento de sua ocorrência, contribuem para o conhecimento e entendimento das relações de fonte-dreno, podendo ainda contribuir com resultados mais práticos, como por exemplo, a simulação de ataque de pragas (insetos e/ou doenças) e avaliação do rendimento de grãos (Silva, 2001).

Para a cultura do meloeiro, por exemplo, os frutos são os maiores drenos da planta, evidenciando a importância do conhecimento sobre o crescimento, a produção e a distribuição de matéria seca entre os órgãos produtivos da planta (Duarte et al., 2008). Para a cultura da soja, observou-se diminuição na produtividade de grãos quando realizada desfolha artificial no estádio R4, pois é nesse estádio que existe a maior demanda de fotoassimilados para os drenos, neste caso, formação e enchimento de vagens (Hirano et al., 2010). Para a cultura do feijoeiro afirma-se que a desfolha tanto artificial ou natural, influencia na relação fonte e dreno da planta, consequentemente, afetando a produtividade final de grãos da cultura (De Melo Moura, 1999). Na cultura da canola, verificouse que durante 0 desenvolvimento das plantas há uma alteração na relação fonte-dreno, pois além da contribuição das folhas e caules, existe a contribuição das síliquas mais desenvolvidas como fonte e as síliquas em início de desenvolvimento apresentam-se como drenos (Mogensen et al., 1997; Diepenbrock, 2000).

Estudos desta ordem são de grande importância para 0 entendimento dos processos metabólicos de fonte-dreno da cultura da canola, pelo fato que, além das folhas, os ramos e as síliquas possam contribuir para produção de fotoassimilados na planta. Torna-se importante a identificação de qual o subperíodo da fase de floração é mais sensível à perda de área foliar em condições ambientais adversas, especificamente os estresses hídricos por excesso ou por déficit de água no solo.

Este trabalho teve por objetivo avaliar a altura média de plantas e a produtividade final de grãos de canola, sob diferentes épocas de desfolhas, em condições à campo, com e sem a utilização de drenagem artificial do solo.

\section{MATERIAL E MÉTODOS}

O experimento foi conduzido em condições de campo no ano agrícola de 2016, na área experimental do Departamento de Fitotecnia da Universidade Federal de Santa Maria (UFSM), localizada na Depressão Central do Rio Grande do Sul $\left(29^{\circ} 43^{\prime}\right.$ 23"S; 53 43' 15" 0; 95 m de altitude).

O clima da região é classificado, de acordo com Köppen, como Cfa (subtropical úmido com verões quentes e sem estação seca definida). 0 solo da área experimental é classificado como Argissolo BrunoAcinzentado Alítico úmbrico (SiBCS, 2013).

Inicialmente foi realizada a coleta de amostras de solo, a fim de fazer a análise química completa e, assim, realizar as devidas aplicações de calcário 
e fertilizantes. O preparo do solo foi realizado de forma convencional, com aração e gradagem, para uniformizar a área.

A semeadura das cultivares Hyola 433, Hyola 76, Diamond e Alht B4, disponibilizadas pela EMBRAPA Trigo Passo Fundo, foi executada no dia 24 de maio de 2016, com uma semeadora artesanal, a qual liberou um número de sementes acima da densidade recomendada. Sendo assim, foi necessário realizar o desbaste do excesso de plantas, quando estas apresentavam 2 a 3 folhas verdadeiras, a fim de deixar a densidade recomendada de aproximadamente 40 plantas $\mathrm{m}^{-2}$. 0 espaçamento entre linhas utilizado foi de 0,4 m e entre planta de 0,05 m.

As adubações de base e de cobertura foram realizadas de acordo com a análise de solo, seguindo as indicações do manual de adubação e calagem para a cultura da canola (SBCS, 2016). Foram efetuadas duas aplicações de ureia em cobertura, com base na estimativa de produtividade de $2000 \mathrm{~kg} \mathrm{ha}^{-1}$ : a primeira quando as plantas se encontravam no estádio V4 (ou seja, plantas com 4 folhas totalmente expandidas) e a segunda aplicação quando as plantas se encontravam no estádio V8, no qual as plantas, em sua maioria, encontravam-se no estádio de surgimento do botão floral (ou seja, plantas no início da fase reprodutiva).

Os tratos culturais e fitossanitários foram realizados de acordo com as necessidades no decorrer do desenvolvimento da cultura, visando mantê-la livre de insetos, pragas, doenças e plantas daninhas, seguindo as indicações técnicas para a cultura. Capinas manuais foram realizadas eventualmente para o controle de plantas daninhas.

0 delineamento experimental utilizado foi delineamento inteiramente casualizado em parcelas subsubdivididas com duas repetições, em um trifatorial $2 \times 4 \times 4$, sendo os níveis fator A solo com e sem drenagem artificial, sorteados na parcela principal; níveis do fator $\mathrm{C}$ diferentes cultivares canola (Hyola 433, Hyola 76, Diamond e Alht B4) na subparcela; e níveis do fator $D$ diferentes épocas de desfolha (início do floração, plena floração, final da floração e sem a retirada de folhas) na subsubparcela. Isso totalizou 64 unidades experimentais, cada uma com a área útil de 0,4 m² (0,4 m de largura $\times 1 \mathrm{~m}$ de comprimento).

A desfolha foi realizada nas plantas localizadas em $1 \mathrm{~m}$ linear na fileira central de cada subparcela, em 3 diferentes estádios de desenvolvimento das plantas: início da floração (IF), que foi caracterizado pela abertura da primeira flor, plena floração (PF) abertura de todas as flores da haste principal e final da floração (FF) caracterizada pela queda da última flor aberta da haste principal, seguindo a escala fenológica descrita por Iriarte e Valetti (2008). Essas desfolhas das plantas de canola foram efetuadas em momentos distintos, respeitando o ciclo de desenvolvimento das diferentes cultivares (Hyola 433, Atth B4, Diamond e Hyola 76).

A altura final de planta foi obtida através da mensuração (com régua graduada, medindo-se do colo ao ápice da planta) de duas plantas em cada unidade experimental e posteriormente realizada a média destes valores.

A colheita das plantas foi realizada a partir da maturação fisiológica dos grãos, sendo efetuada manualmente quando os grãos mudaram da cor verde para a cor marrom na porção intermediária da inflorescência principal, colhendo-se todas as plantas da área útil de cada tratamento, localizadas na fileira central de cada parcela. Posteriormente, as plantas cortadas foram acomodadas em um galpão, para que tivessem a sua umidade reduzida (em torno de 10\%), facilitando a atividade da debulha e limpeza dos grãos.

Para obtenção dos dados de produtividade, foram realizadas a pesagem de grãos de cada tratamento em gramas (g), com uma balança de precisão com 3 casas decimais e posterior conversão para $\mathrm{g} \mathrm{m}^{-2}$. Estes dados foram submetidos à análise da variância com $5 \%$ de probabilidade de erro e realizada a comparação entre médias com o teste de Scott-Knott no programa estatístico SISVAR (Ferreira, 2011).

Os dados diários de chuva, temperatura mínima e máxima do ar, velocidade do vento e radiação solar foram obtidos da Estação Meteorológica Automática de Santa Maria e os dados de umidade relativa do ar da Estação Meteorológica Convencional, devido a falhas nos dados da estação automática, ambas pertencentes ao $8^{\circ}$ Distrito de Meteorologia do Instituto Nacional de Meteorologia (INMET), situada a $50 \mathrm{~m}$ da borda Norte do experimento. Os dados históricos mensais de chuva, temperatura máxima e mínima do ar em Santa Maria foram obtidos na publicação de dados normais do INMET do período de 1961 e 1990, com objetivo de fazer a comparação com 0 ano de execução do estudo. 
Para caracterizar as condições hídricas do solo foi calculado o balanço hídrico sequencial (BHS) diário durante o período de condução do experimento no ano de 2016, com o método proposto por Thornthwaite e Mather (1955) descrito por Pereira (2005). Utilizou-se a adaptação de Dourado Neto et al. (1999) para ponderar a variação diária da capacidade de armazenamento de água no solo (CAD) ao longo do ciclo de desenvolvimento das plantas, em função do crescimento radicular em profundidade.

\section{RESULTADOS E DISCUSSÃO}

Nas Figuras 1 e 2 são apresentados os dados das condições meteorológicas e o balanço hídrico sequencial, respectivamente, ao longo do ciclo de desenvolvimento da cultura da canola. Observa-se a disponibilidade hídrica para a cultura através dos dados de precipitação, para o período de duração entre a semeadura e a colheita da última parcela do experimento, que compreende entre os meses de maio a outubro, assim como a temperatura máxima e mínima do ar correspondente ao mesmo período.

Figura 1. Médias de precipitações, de temperaturas máximas e mínimas para o município de Santa Maria, RS, no ano de 2016, durante os meses do ciclo da cultura de canola: maio, junho, julho, agosto, setembro e outubro.

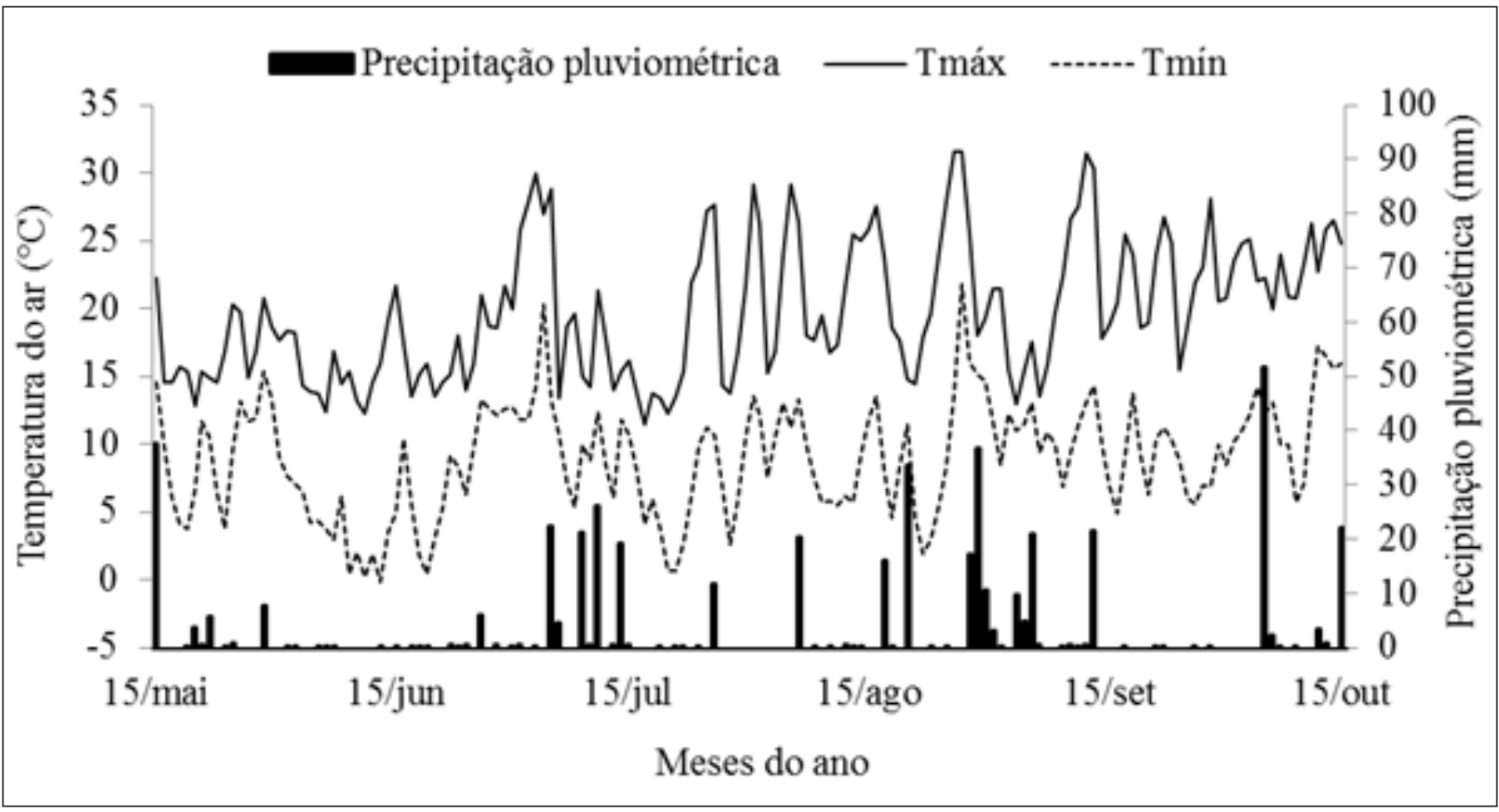

Figura 2. Armazenamento de água diário, em função do balanço hídrico sequencial diário, durante o período de 24/05/2016 a 11/10/2016 para um Argissolo Vermelho distrófico arênico cultivado com canola. Santa Maria, RS.

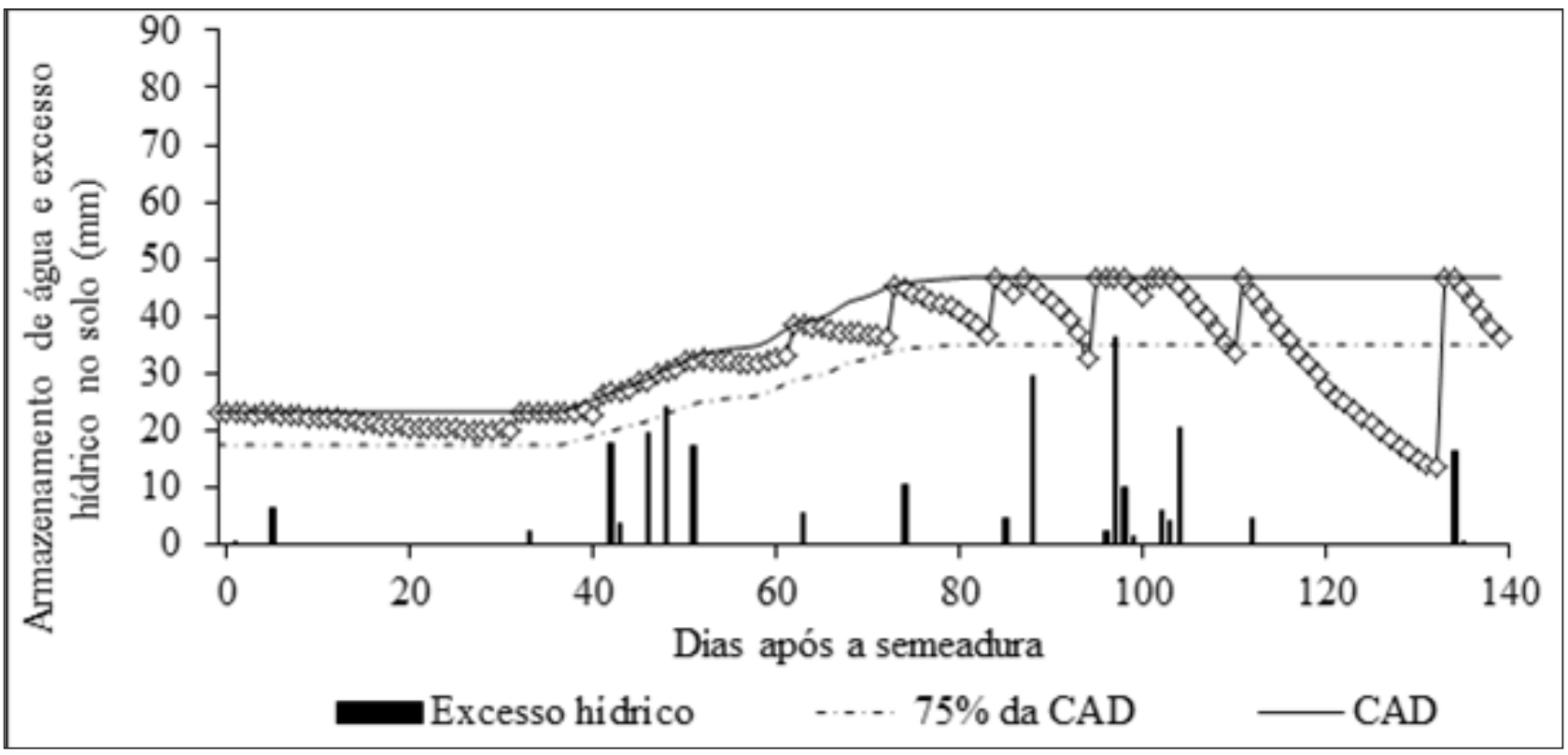


Em todos os meses analisados a precipitação apresentou-se abaixo da normal climatológica, com acumulados mensais de: maio $(55,8 \mathrm{~mm})$, junho $(9,4 \mathrm{~mm})$, julho $(107,8 \mathrm{~mm})$, agosto $(139,0 \mathrm{~mm})$, setembro $(59,8 \mathrm{~mm})$ e outubro $(80,2 \mathrm{~mm})$, não ocorrendo excessos hídricos em relação a normal climatológica. Em relação à demanda hídrica para cultura de canola durante o ciclo produtivo, o volume de chuva acumulado foi de aproximadamente 400 $\mathrm{mm}$, ficando dentro do recomendado para a cultura que é em torno de 300 a $500 \mathrm{~mm}$ de precipitação (Tomm, 2009).

A semeadura foi realizada quando o solo se encontrava entre a capacidade máxima de armazenamento de água (CAD) e $75 \%$ da CAD, sendo que após a semeadura ocorreram vários eventos de saturação do solo. 0 primeiro aos cinco dias após a semeadura e o seguinte aos 40 dias depois da semeadura, onde o solo permaneceu cinco dias em condição de saturação. Outro período em que o solo permaneceu sob excesso hídrico foi dos 90 aos 105 DAS, quando as plantas se encontravam na fase de floração. Na maioria dos dias desse período experimental a umidade do solo permaneceu entre a CAD e $75 \%$ da CAD. Apenas no final do ciclo ocorreu um período em que as plantas ficaram 20 dias sob umidade do solo abaixo de $75 \%$ da CAD (Figura 2).

Um período de excesso hídrico seguido de um período de déficit hídrico pode submeter a planta a um estresse hídrico mais intenso devido ao seu sistema radicular reduzido limitar a absorção de água em um menor volume de solo. Nessa condição, provavelmente a planta destina mais energia para produção de raízes, em detrimento do crescimento da parte aérea.

Observa-se que em todos os meses do ciclo da cultura, as temperaturas atingiram níveis abaixo ou acima do ideal para um bom crescimento e desenvolvimento das plantas (Figura 1). No mês de junho, quando as plantas se encontravam no estádio de plântulas a roseta, ocorreram temperaturas do ar próximas a $0^{\circ} \mathrm{C}$. Sabendo-se que a temperatura na relva é menor, considera-se que houve formação de geada, prejudicando o desenvolvimento ideal da cultura, pois é nos estádios de plântulas e de floração que a cultura é mais prejudicada, afetando a sua produtividade final de grãos (Dalmago et al., 2008; Tomm et al., 2009). Nos meses de julho e agosto também ocorreram temperaturas mínimas do ar próximas a $0^{\circ} \mathrm{C}$, período este em que as plantas estavam em fase de floração.

Nos meses de julho, agosto e setembro ocorreram picos de temperaturas máximas do ar acima do limite superior recomendado para a cultura que é de $27^{\circ} \mathrm{C}$. A partir desta temperatura, principalmente no estádio de floração, notamse danos a cultura como abortamento de flores e síliquas no início da formação (Dalmago et al., 2010; Tomm et al., 2009).

A análise da variância realizada não apontou interação tripla significativa entre os fatores avaliados, tanto para os dados de altura média final de plantas como para produtividade final de grãos.

Para a variável altura final de planta (Tabela 1), pode-se observar que quanto mais tarde ocorrer à desfolha, ou seja, a partir do estádio de plena floração, menor será a interferência desta na altura média das plantas, pois há um aumento na altura média das plantas de todas as cultivares analisadas, sendo o início da floração o subperíodo mais afetado com a retirada das folhas. Esses resultados foram semelhantes aos de Diogo et al. (1997), concluindo que a há redução no crescimento da planta da cultura da soja, ou seja, plantas menores para as desfolhas realizadas até a plena floração da cultura. A hipótese é que a canola seja sensível a perda de folhas na fase inicial da floração devido ao fato de que as folhas são, até então, as únicas estruturas da planta responsáveis pela sintetização de fotoassimilados que seriam utilizados para a formação das estruturas reprodutivas. No entanto, a partir do estádio de plena floração, a planta já apresenta síliquas formadas, além de um maior número de ramos, os quais compensam, em parte, a perda de folhas e acabam contribuindo na produção de fotoassimilados. 
Tabela 1. Altura média de planta $(\mathrm{cm})$ para interação significativa entre cultivares de canola (Diamod, Hyola 433, Hyola 76, Alht B4) e épocas de desfolha (testemunha, início da floração, plena floração e final da floração) para cultura de canola. Santa Maria, RS.

\begin{tabular}{lcccc}
\hline \multirow{2}{*}{ Cultivar } & \multicolumn{4}{c}{ Época de desfolha } \\
\cline { 2 - 5 } & Testemunha & Início Floração & Plena Floração & Final Floração \\
\hline Hyola 76 & $122,88 \mathrm{aB}$ & $97,88 \mathrm{aD}$ & $112,5 \mathrm{aC}$ & $135,62 \mathrm{aA}$ \\
Alth B4 & $107,72 \mathrm{bB}$ & $99,63 \mathrm{aB}$ & $116,0 \mathrm{aA}$ & $121,0 \mathrm{bA}$ \\
Hyola 433 & $106,78 \mathrm{bA}$ & $95,87 \mathrm{aA}$ & $99,5 \mathrm{bA}$ & $106,63 \mathrm{cA}$ \\
Diamond & $100,84 \mathrm{bA}$ & $94,64 \mathrm{aA}$ & $95,63 \mathrm{bA}$ & $108,0 \mathrm{cA}$ \\
\hline
\end{tabular}

*Médias seguidas por letras minúsculas iguais na coluna e maiúsculas iguais na linha não diferem significativamente pelo teste de Scott-Knott a $5 \%$ de probabilidade de erro.

Fonte: Autor, 2017.

Cabem destacar as cultivares Hyola 433 e Diamond, as quais mantiveram suas alturas constantes, mesmo sendo realizada a retirada das folhas em diferentes épocas da fase reprodutiva. Deste modo, evidencia-se a não total dependência da área foliar como fonte, para essas cultivares, na produção de fotoassimilados para o crescimento e desenvolvimento de caule e ramos. A cultivar Hyola 76, na testemunha, apresentou-se como a cultivar de maior altura média de planta, característica essa inerente a cultivar, que a nível comercial atinge a altura média de planta de $115 \mathrm{~cm}$.
$\mathrm{Na}$ interação entre o fator drenagem do solo e cultivares de canola (Tabela 2), observa-se que para todas as cultivares houve diferença significativa entre os tratamentos, evidenciando a influência deste fator nas médias finais de altura. No sistema sem dreno as médias de altura de planta foram inferiores as médias de altura do tratamento com dreno, isso pode ser desencadeado devido aos estresses ocasionados pelos excessos hídricos durante os ciclos das cultivares que ocorrem no fator sem dreno, influenciando o crescimento e desenvolvimento normal das plantas, diminuindo a altura final das mesmas.

Tabela 2. Altura média de planta $(\mathrm{cm})$ da interação significativa entre as diferentes condições hídricas do solo (com dreno e sem dreno) e das diferentes cultivares de canola (Diamond, Hyola 433, Hyola 76, Alht B4). Santa Maria, RS.

\begin{tabular}{lcccc}
\hline \multirow{2}{*}{ Condição hídrica do solo } & \multicolumn{4}{c}{ Cultivares } \\
\cline { 2 - 5 } & Hyola 433 & Alht B4 & Diamond & $125,7 \mathrm{aA}$ \\
\hline Com dreno & $105,34 \mathrm{aB}$ & $119,36 \mathrm{aA}$ & $109,85 \mathrm{aB}$ & $108,73 \mathrm{bA}$ \\
Sem dreno & $99,04 \mathrm{bA}$ & $102,81 \mathrm{bA}$ & $89,7 \mathrm{bB}$ & \\
\hline
\end{tabular}

*Médias seguidas por letras minúsculas iguais na coluna e maiúsculas iguais na linha não diferem significativamente pelo teste de Scott-Knott a $5 \%$ de probabilidade de erro.

Fonte: Autor, 2017

Analisando a altura de cada cultivar nos tratamentos com dreno e sem dreno, todas apresentaram o mesmo comportamento, com menores médias no tratamento sem dreno, coloca-se como explicação a este comportamento, devido ao estresse por excesso hídrico que planta teve durante o seu ciclo produtivo, afetando o crescimento e desenvolvimento ideal de caules e ramos, diminuindo a média de altura de plantas. Salienta-se novamente a cultivar Hyola 76 e também a Alht B4, devido as suas médias de alturas superiores as outras cultivares, tanto para o fator com dreno como para o fator sem dreno.
Na Tabela 3 são expostos os valores de altura média de plantas dos tratamentos com dreno e sem dreno em relação aos fatores das diferentes épocas de desfolha. Pode-se notar que houve diferença significativa entre os tratamentos com dreno e sem dreno, para todas as épocas de desfolha realizadas e também para o nível testemunha, sendo que as maiores médias de altura de planta ocorreram no tratamento com drenagem artificial. 
Tabela 3. Altura média de planta $(\mathrm{cm})$ para interação significativa entre diferentes condições hídricas do solo (com dreno e sem dreno) e épocas de desfolha (testemunha, início da floração, plena floração e final da floração) na cultura de canola. Santa Maria, RS.

\begin{tabular}{lcccc}
\hline \multirow{2}{*}{ Condição hídrica do solo } & \multicolumn{4}{c}{ Época de desfolha } \\
\cline { 2 - 5 } & Testemunha & Início Floração & Plena Floração & Final Floração \\
\hline Com dreno & $116,06 \mathrm{aB}$ & $101,01 \mathrm{aC}$ & $116,19 \mathrm{aB}$ & $127,0 \mathrm{aA}$ \\
Sem dreno & $103,05 \mathrm{bA}$ & $93,0 \mathrm{bB}$ & $95,63 \mathrm{bB}$ & $108,62 \mathrm{bA}$ \\
\hline
\end{tabular}

*Médias seguidas por letras minúsculas iguais na coluna e maiúsculas iguais na linha não diferem significativamente pelo teste de Scott-Knott a $5 \%$ de probabilidade de erro.

Fonte: Autor, 2017.

Em relação às diferentes épocas de desfolha, pode-se observar que as médias de altura no início da floração foram menores e as desfolhas no final da floração foram as que apresentaram as maiores médias de altura. Isso pode ser explicado pela resposta da planta em compensação a área foliar perdida, com a expansão de seu caule e ramos para maior captação de radiação solar, aumentado a altura média final da planta.

$\mathrm{Na}$ Tabela 4 estão apresentadas as médias de produtividade de grãos $\left(\mathrm{g} \mathrm{m}^{-2}\right)$ da interação entre os fatores drenagem do solo (com dreno e sem dreno) e épocas de desfolhas (testemunha, início da floração, plena floração e final da floração) para a cultura da canola. Observa-se uma diferença significativa de produtividade entre os tratamentos com dreno e sem dreno em todas as épocas em que foi realizada a desfolha, além do tratamento testemunha, sendo que o tratamento sem dreno apresentou as menores médias para esta variável analisada, isso devido aos estresses provenientes dos excessos hídricos que ocorreram ao longo do ciclo, o que afetou o rendimento final de grãos.

Tabela 4. Produtividade média de grãos $\left(\mathrm{g} \mathrm{m}^{-2}\right)$ de canola em duas condições hídricas do solo (com dreno e sem dreno) e em diferentes épocas de desfolha (testemunha, início da floração, plena floração e final da floração) com interação significativa. Santa Maria, RS.

\begin{tabular}{lcccc}
\hline \multirow{2}{*}{ Condição hídrica do solo } & \multicolumn{4}{c}{ Época de desfolha } \\
\cline { 2 - 5 } & Testemunha & Início Floração & Plena Floração & Final Floração \\
\hline Com dreno & $91,88 \mathrm{aA}$ & $27,52 \mathrm{aD}$ & $38,68 \mathrm{aC}$ & $65,18 \mathrm{aB}$ \\
Sem dreno & $72,39 \mathrm{bA}$ & $16,53 \mathrm{bB}$ & $14,24 \mathrm{bB}$ & $19,9 \mathrm{bB}$ \\
\hline
\end{tabular}

*Médias seguidas por letras minúsculas iguais na coluna e maiúsculas iguais na linha não diferem significativamente pelo teste de Scott-Knott a 5\% de probabilidade de erro.

Fonte: Autor, 2017.

O tratamento testemunha foi o que apresentou média superior comparado aos demais níveis do fator época de desfolha, tanto para o nível com dreno tanto para o nível sem dreno do fator drenagem do solo. Este resultado já era esperado pelo fato de as plantas permanecerem com as folhas até sua senescência natural, provando a importância da área foliar para as plantas até o final do ciclo para produtividade final de grãos.

Observa-se que no tratamento com dreno todas as diferentes épocas de desfolhas, incluindo o tratamento testemunha, tiveram diferença significativa, enquanto que no tratamento SD não ocorreu 0 mesmo. Supõe-se que para o tratamento sem dreno as plantas tiveram sua produtividade final de grãos comprometida devido aos estresses causados pelos excessos hídricos, antes mesmo das plantas estarem na fase reprodutiva. 0 excesso hídrico diminui a disponibilidade de $\mathrm{O}_{2}$ para as raízes, diminuindo também a translocação de fotoassimilados e de água na planta, afetando negativamente a produtividade ( Schöffel et al., 2001).

$\mathrm{Na}$ Tabela 5, destaca-se a média de produtividade final de grãos no nível de testemunha da cultivar Alht B4, apresentando o menor valor dentre as cultivares analisadas, podendo ser uma cultivar mais sensível ao ambiente onde foi conduzido o ensaio, em relação às outras cultivares. Salienta-se 
também a baixa produtividade final de grãos no fator desfolha ao final da floração para a cultivar Alht B4 , evidenciando a necessidade da área foliar para essa cultivar até o final de seu ciclo reprodutivo para que não ocorram perdas significativas na produtividade de grãos. Todas as cultivares tiveram diminuição significativa de produtividade em início da floração e plena floração, semelhantes aos resultados obtidos para a cultura do feijão, a qual apresentou maior redução de produtividade com a desfolha total no estádio R6, ou seja, no estádio de floração da planta (Moura, 1999). Mesmo sem apresentar diferença significativa entre os genótipos, destaca-se a cultivar Diamond que obteve maior produtividade do que os demais materiais, quando realizada desfolha em plena floração e também no final da floração, apresentandose assim como uma cultivar com maior estabilidade de rendimento de grãos, mesmo com a ocorrência do estresse proveniente da retirada das folhas $e$ das adversidades oriundas do ambiente. A cultivar Diamond apresentou maior produtividade, enquanto a cultivar Alht B4 apresentou a menor produtividade final de grãos para o tratamento testemunha, ou seja, sem a retirada das folhas.

Tabela 5. Produtividade média de grãos $\left(\mathrm{g} \mathrm{m}^{-2}\right.$ ) entre as cultivares de canola (Diamod, Hyola 433, Hyola 76, Alht B4) e as épocas de desfolha (testemunha, início da floração, plena floração e final da floração) com interação significativa. Santa Maria, RS.

\begin{tabular}{lcccc}
\hline \multirow{2}{*}{ Cultivar } & \multicolumn{4}{c}{ Época de desfolha } \\
\cline { 2 - 5 } & Testemunha & Início Floração & Plena Floração & Final Floração \\
\hline Diamond & $107,05 \mathrm{aA}$ & $19,93 \mathrm{aD}$ & $33,84 \mathrm{aC}$ & $56,35 \mathrm{aB}$ \\
Hyola 433 & $91,13 \mathrm{bA}$ & $29,93 \mathrm{aC}$ & $25,35 \mathrm{aC}$ & $46,81 \mathrm{aB}$ \\
Hyola 76 & $75,09 \mathrm{cA}$ & $20,56 \mathrm{aC}$ & $23,35 \mathrm{aC}$ & $41,52 \mathrm{aB}$ \\
Alth B4 & $55,27 \mathrm{dA}$ & $17,07 \mathrm{aB}$ & $23,30 \mathrm{aB}$ & $25,48 \mathrm{bB}$ \\
\hline
\end{tabular}

*Médias seguidas por letras minúsculas iguais na coluna e maiúsculas iguais na linha não diferem significativamente pelo teste de Scott-knott a $5 \%$ de probabilidade de erro.

Fonte: Autor, 2017.

Deste modo, o uso de um sistema de drenagem do solo é imprescindível para possibilitar o cultivo de canola em áreas características de várzea e, distintos genótipos respondem de forma diferente quanto a sua produtividade quando sofrem a perda de folhas em diferentes estádios fenológicos a partir da fase reprodutiva do seu ciclo de desenvolvimento.

De modo geral, tanto a produtividade final de grãos e a altura média de plantas de canola são afetadas significativamente em função do fator drenagem do solo, além das diferentes épocas em que é realizada a desfolha das plantas, sendo que o subperíodo da fase de floração da canola mais sensível à perda de folhas é o início da floração, seguido da plena floração da cultura.

\section{REFERÊNCIAS BIBLIOGRÁFICAS}

Comissão de Química e Fertilidade do Solo - RS/SC. Manual de calagem e adubação para os Estados do Rio Grande do Sul e de Santa Catarina. Sociedade Brasileira de Ciência do Solo. 2016; 376p.
Conab - Companhia Nacional de Abastecimento. Séries históricas, 2017. Disponível em: <http://www. conab.gov.br/conteudos.php?a=1252\&Pagina objcmsconteudos=2\#A_objcmsconteudos>. Acesso em 03 de agosto de 2017.

Dalmago, G. A.; Cunha, G. R. da; Tomm, G. O.; Pires, J. L. F.; Santi, A.; Müller, A. L.; Bolis, L. M. Aclimatação ao frio e dano por geada em canola. Pesquisa Agropecuária Brasileira, 2010, 45, 9, 933943. Disponível em: <http://www.scielo.br/pdf/pab/ v45n9/a01v45n9.pdf>. Acesso em:

Diepenbrock, W. Análise de rendimento de colza de inverno (Brassica napus L.): uma revisão. Field Crops Research, 2000, 67, 35-49.

Diogo, A. M.; Sediyama, T.; Rocha, V. S; Sediyama, C. S. Influência da remoção de folhas, em vários estádios de desenvolvimento, na produção de grãos e em outras características agronômicas da soja (Glycine max (L.) Merrill). Revista Ceres, 1997, 44, 253. http://www. ceres.ufv.br/ojs/index.php/ceres/article/view/2419/423 
Duarte, T. S.; Peil, R. M. N. Relações fonte: dreno e crescimento vegetativo do meloeiro. Horticultura brasileira, 2010 28, 3, 271-276. http://www.scielo.br/ $\mathrm{pdf} / \mathrm{hb} / \mathrm{v} 28 \mathrm{n} 3 / \mathrm{v} 28 \mathrm{n} 3 \mathrm{a} 05 . \mathrm{pdf}$

Duarte, T. S.; Peil, R. M. N.; Montezano, E. M. Crescimento de frutos do meloeiro sob diferentes relações fonte: dreno. Horticultura brasileira, 2008, 26, 3. http://www.scielo.br/pdf/hb/v26n3/10.pdf

Ferreira, D.F. SISVAR: a computer statistical analysis system. Ciência a Agrotecnologia, 2011, 35, 6, 1039 1042.

Hirano, Mario; Hikishima, M.; Silva, A. J. da; Xavier, S. A.; Canteri, M. G. Validação de escala diagramática para estimativa de desfolha provocada pela ferrugem asiática em soja. Summa phytopathologica, 2010, 36, 248-250. http:// http://www.scielo.br/pdf/sp/v36n3/ v36n3a12.pdf

Iriarte, L. B.; Valetti, O. Cultivo de colza. Buenos Aires: Instituto Nacional de Tecnología Agropecuaria, 2008.
Mogensen, V. O.; Jensen, C. R.; Mortensen, G; Andersen, M. N.; Schjoerring, J. K.; Thage, J. H.; Koribidis, J.. Fotossíntese e adaptação à seca de colza cultivada em campo (Brassica napus). Revista Europeia de Agronomia, 1997, 6, 295-307. https://www.sciencedirect.com/science/article/pii/ S1161030196020527

Moura, de G., M. Efeito do desfolhamento no rendimento do feijoeiro. Pesquisa Agropecuária Brasileira, 1999, 34, 1, 57-62. http://www.scielo.br/pdf/ pab/v34n1/8709.pdf

SiBCS (Sistema brasileiro de classificação de solos), $3^{a}$ edição, Embrapa solos, 2013. 353 p.

Edgar Ricardo Schöffel, E. R.; Saccol, A. V.; Manfron, P. A.; Medeiros, S. L. P. Excesso hídrico sobre os componentes do rendimento da cultura da soja. Revista Ciência Rural, 2001, 31, 1, 7-12. http://www. scielo.br/pdf/cr/v31n1/a02v31n1.pdf

Tomm, G. O.; Ferreira, P. E. P.; Aguiar, J. L. P. de; Castro, A. M. G. de; Lima, S. M. V.; Moriet, C. de. Tecnologia para produção de canola no Rio Grande do Sul. 2009. http://www.cnpt.embrapa.br/biblio/do/p_ do118.pdf. 